\title{
ANALYSIS OF NON-UNIFORM DISTRIBUTION OF THE EQUIVALENT STRESS BY SELECTED MULTIAXIAL FATIGUE CRITERIA IN BUTT-WELDED JOINT
}

\author{
Przemysław STASIUK*, Aleksander KAROLCZUK*, Wiesław KUCZKO*,* \\ *Opole University of Technology, Faculty of Mechanical Engineering, \\ Department of Mechanics and Machine Design, ul. Prószkowska 76, 45-758 Opole, Poland \\ "Poznan University of Technology, Chair of Management and Production Engineering, \\ Department of Mechanical Engineering and Management, PI. M. Skłodowskiej-Curie 5, 60-965 Poznań, Poland \\ przemyslaw.stasiuk@wp.pl, a.karolczuk@po.opole.pl, wieslaw.kuczko@doctorate.put.poznan.pl

\begin{abstract}
Welded joints are areas of increased stresses in construction. The reason for this phenomenon is associated with the nonhomogeneous mechanical, structural and geometrical properties of the weld seams. Generally, in the majority of the calculation it is assumed that the shape of the weld is uniform over the entire length and it is not deviating from the theoretical one. This article shows the distribution of stress in the butt-weld made of S355J2+N steel specimens. The shape of a joint was transferred to the finite element analysis by application of 3D scanning. Selected multiaxial fatigue criteria and probability mass function were used for a description of the results. Theoretical model prepared for comparison to the scanned joints was consistent with recommendations of International Institute of Welding for the effective notch method.
\end{abstract}

Key words: FEM Analysis, Weld, Stress Concentration, 3D Scanning

\section{INTRODUCTION}

Welding is a widely used way to connect elements. This method gives designers the possibility to freely form structures in the manufacturing workshop or on site. Despite the undeniable advantages, this process also has some drawbacks. The welding operation causes residual stress, changes in the structure of the material, forming a structural notch (Blacha et al., 2011a) and also a geometry notch studied in (Blacha et al., 2011b). Obviously, the influence of these defects can be reduced by heat treatment - the heterogeneity of structure and residual stresses, and machining - geometry notch. However, this type of treatment carries a considerable financial outlay. Popularity of welding makes attempts to find methods to better understanding the changes occurring in the material and the effect on the strength of connections is now desirable.

Recent development in 3D laser scanning enables considering almost real weld geometry in fatigue analysis (Alam et al., 2010; Hou, 2007). This field of research requires further investigation which is undertaken in the present article. Specimens were made from S355J2+N steel - a material widely used in the industry. Surface models obtained by the 3D scanning were converted into solid model, additionally prepared and calculated by the finite element method (FEM). The results were compared to those obtained from the model of the weld with the welding toe radius equal to $1 \mathrm{~mm}$, i.e. value recommended by International Institute of Welding (IIW) (Hobbacher 2008) for steel welding joints subjected to cyclic loading. An originality of the present work is building the probability mass function (pmf) (Stewart 2011) of stress for both discrete models of the joints. Selected fatigue criteria were used to calculate the pmf of the equivalent stresses. The aim of the research is to calculate realistic equivalent stress distribution in the butt weld joints and comparison of the result to experimentally obtained fatigue lives.

\section{PREPARATION OF THE SPECIMENS}

The specimens were made from the two $6 \mathrm{~mm}$ thick metal $(\mathrm{S} 355 \mathrm{~J} 2+\mathrm{N})$ sheets with the dimensions $100 \times 1000 \mathrm{~mm}$. Plasma cutting was used to prepare elements. Edges of the plates were milled in order to create correct $\mathrm{V}$ butt joint. Welding was conducted by MAG method, with $1.2 \mathrm{~mm}$ wire, in $\operatorname{Ar}(92 \%)$ and $\mathrm{CO}_{2}$ $(8 \%)$ gas shield, without using clamps. The seam was tested by ultrasonic method. The specimens with geometry presented in Fig.1 were obtained from middle part of welded element by saw cutting and milling.
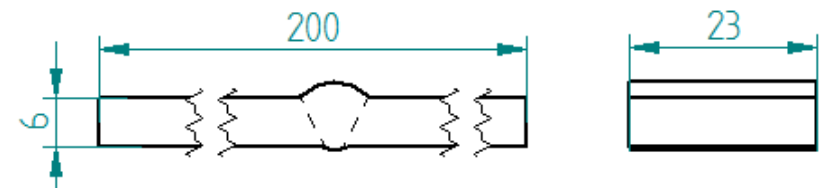

Fig. 1. Geometry of the specimens

\subsection{D scanning}

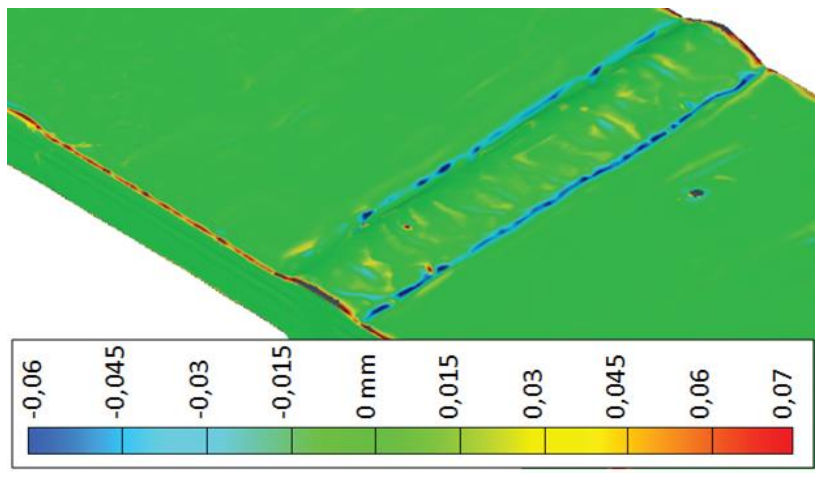

Fig. 2. Mapping accuracyin $\mathrm{mm}$ for stereolithography file 
3D scanning was used to create numerical models of the specimens. The applied method gives a maximum possibility of mapping accuracy up to $0.02 \mathrm{~mm}$. For each side of the specimen 5 scans were performed. Particular scans were combined using markers which were fixed on the specimen surface. A triangle mesh was applied and used as an output. In the next step, files were converted into stereolithography ( ${ }^{*}$. stl). In Fig.2 difference between scanned data and geometry from stl file for exemplary sample is shown.

\subsection{Preparing FEM Analysis}

In order to speed up the calculations in FEM program, the specimen grips were not modeled. The models were converted into Solid Edge part (*.par). This type of files could be imported directly into Femap (FEM program). The size of finite elements is not uniform and the density of mesh is considerably increased in the area where stress concentration is expected (Fig.3). Preliminary analysis was conducted to determine the appropriate mesh size. Finally, the maximum length of finite element equal to $0.05 \mathrm{~mm}$ in the welding toe was chosen (Fig.3).



Fig. 3. The geometry of the models with mesh

In the fatigue tests the specimens were subjected to push-pull loading under nominal stress amplitude equal to $180 \mathrm{MPa}$. Thus, the models were calculated under tensile $\sigma_{\text {nom }}=180 \mathrm{MPa}$ stress applied to the surface as showed in Fig.3. Loaded surface was constrained in one of his longest edge by blocking translation in $y$ and $z$ axes. In the opposite site of the model, the surface is fixed in all directions. The applied constrains imitate fixing in the fatigue testing machine (hydraulic grips).

Besides the scanned specimens the geometry of theoretical model prepared according to International Institute of Welding (Hobbacher 2008) was built for additional FEM analysis. This theoretical model is presented in Fig.4. A welding toe radius equal to $1 \mathrm{~mm}$ is a value suggested by IIW for the effective notch method. The model was prepared and calculated (mesh and constrains) in the same way as models from scanned specimens.
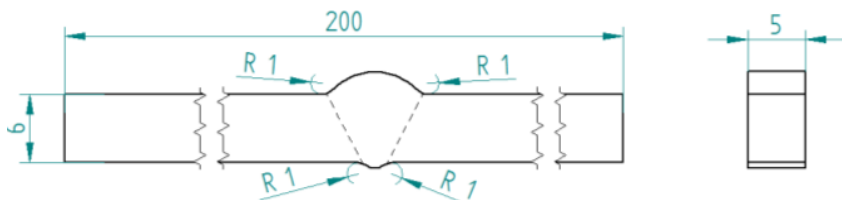

Fig. 4. Geometry of the theoretical model

\section{RESULTS OF THE FEM ANALYSIS}

Static analysis was performed using a linear-elastic model of the body $(E=205 G P a, v=0.3)$. Results in the form of principal stresses: $\sigma_{1}, \sigma_{2}, \sigma_{3}$ and model geometry were transferred into Matlab software in order to perform subsequent calculations. In the commonly applied (in metallic materials) fatigue criteria (Karolczuk et al., 2005) the multiaxial stress state is reduced to the equivalent one which is used in the fatigue life calculations. The function that reduces multiaxial stress state to the equivalent one depends on hypotheses that were formulated by various researchers. Four well known equivalent stresses were selected to calculate their distribution in butt weld joints. The chosen equivalent stresses have the advantage that they can be presented in the function of principal stresses which simplifies the FEM and subsequent calculations. The first two equivalent stresses came from static hypothesis, i.e. the Huber-Mises-Hencky hypothesis (Eq.1) and the maximum principal stress hypothesis (Eq.2)

$\sigma_{H M H}=\sqrt{\frac{1}{2}\left[\left(\sigma_{1}-\sigma_{2}\right)^{2}+\left(\sigma_{2}-\sigma_{3}\right)^{2}+\left(\sigma_{3}-\sigma_{1}\right)^{2}\right]}$,

$\sigma_{S 1}=\sigma_{1}$.

The last two equivalent stresses came from the well-known fatigue criteria, i.e. the Matake criterion (Eq.3) and the Dang Van criterion (Eq.4). Matake (1977) assumes that maximum shear stress $\frac{\sigma_{1}-\sigma_{3}}{2}$ and normal stress $\frac{\sigma_{1}+\sigma_{3}}{2}$ on the plane of maximum shear stress are critical in respect to fatigue damage

$\sigma_{M A}=\frac{\sigma_{1}-\sigma_{3}}{2}+k \frac{\sigma_{1}+\sigma_{3}}{2}, k=2 \frac{\tau_{a f}}{\sigma_{a f}}-1$,

where: $\tau_{a f}, \sigma_{a f}$ are the fatigue limits for fully reversed torsion and push-pull loadings $\left(\tau_{a f}=157 \mathrm{MPa}, \sigma_{a f}=204 \mathrm{MPa}\right)$ (Karolczuk 2008). According to Dang Van (1993) the hydrostatic stress $\frac{\sigma_{1}+\sigma_{2}+\sigma_{3}}{3}$ is more important in fatigue analysis than the normal stress

$\sigma_{D V}=\frac{\sigma_{1}-\sigma_{3}}{2}+a \frac{\sigma_{1}+\sigma_{2}+\sigma_{3}}{3}, a=\frac{\tau_{a f}-0.5 \sigma_{a f}}{\frac{\sigma_{a f}}{3}}$.

Inhomogeneity of stress distribution in weld joint is clearly presented by probability mass function

$\operatorname{pmf}\left(\sigma_{H I P}\right)=\operatorname{Prob}\left\{\left[\sigma=\sigma_{H I P}\right]\right\}=\frac{\mathrm{V}\left(\sigma=\sigma_{H I P}\right)}{V_{0}}$,

where $\sigma$ HIP is a value of stress according to particular hipothesis or criterium ( $H I P=H M H, S 1, M A, D V), V\left(\sigma=\sigma_{H I P}\right)$ is a volume of material in weld area and heat affected zone with certain value of the stress $\sigma_{H I P}, V_{0}$ is a considered volume of material. Probability mass function (Eq.5) is a function that gives the probability of occurrance of a certain equivalent stress value in the weld joint.

In Fig. 5 an exemplary equivalent stress distribution in one of the weld joint is shown.

Figs. 6-9 presents the pmf functions for the specimens and for a theoretical model (showed in red colour). Maximum values of stress for each specimen are shown in Tab. 1. The bold and underlines values in Tab. 1 show the most locally stressed specimen. According to that computation it is expected that the specimen 1 will exhibit the shortest fatigue life. 


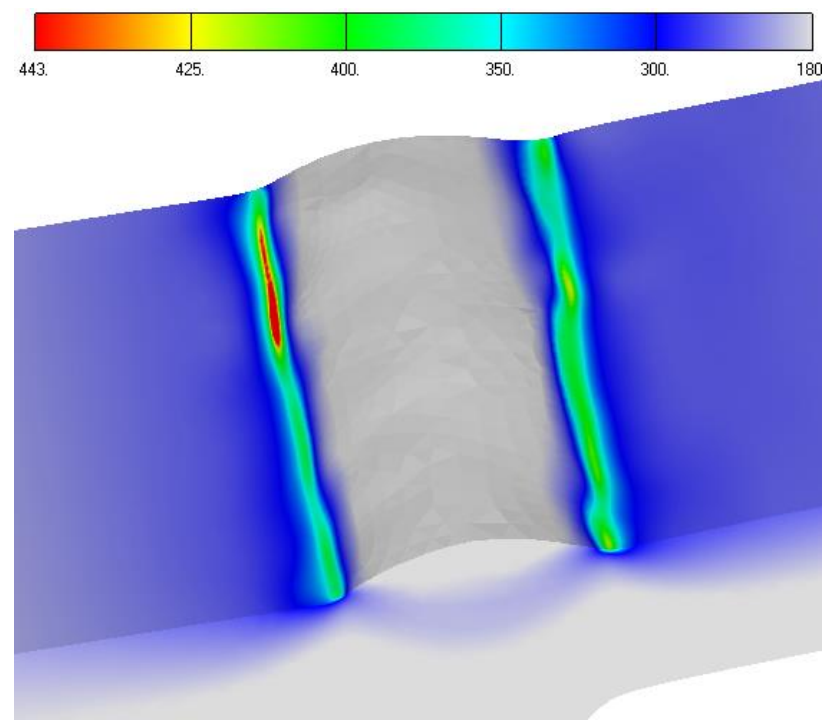

Fig. 5. The Huber-Mises-Hencky stress distribution

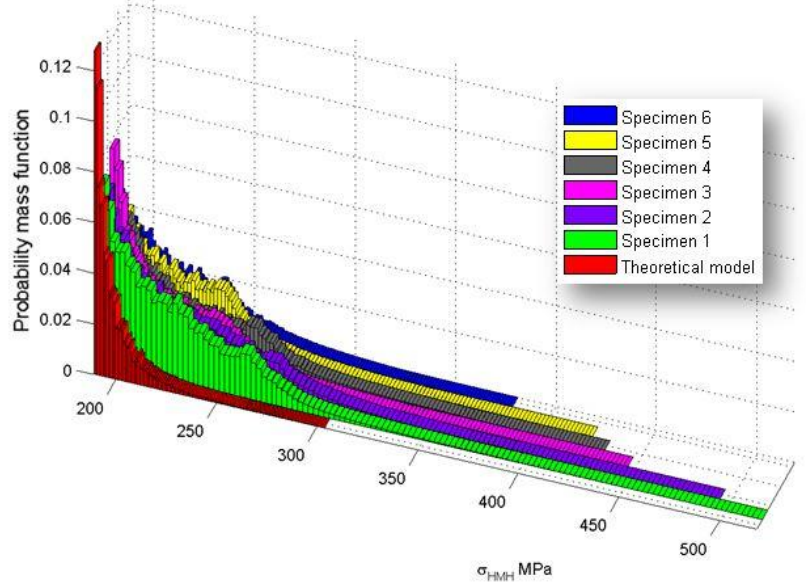

Fig. 6. Probability mass function for the Huber-Mises-Hencky stress

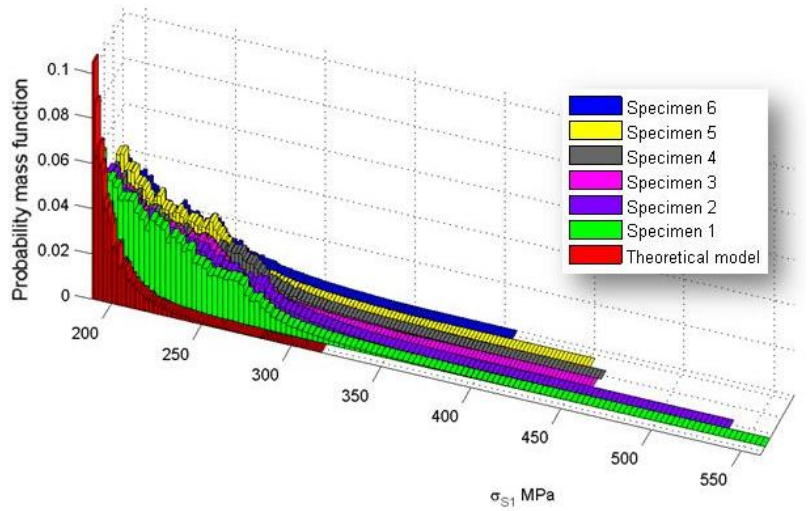

Fig. 7. Probability mass function for the Maximal Principal Stress

Comparing the pmf of equivalent stresses obtained for the scanned specimens and the theoretical model it is concluded that the pmf of theoretical model has only one extreme that corresponds to the nominal stress. The pmf for the Dang Van and Matake criteria differs from the other criteria because theses stresses are equivalent to shear stresses (to the torsion tests) instead of tensile stresses (to the push-pull test). Moreover, the pmf for scanned specimens shows that higher equivalent stresses occupy larger volume of material than it is for the theoretical model. The maximal values of computed stresses for each hypothesis presented in table 1 vary in proportional way, i.e. the highest stresses for all hypotheses exist in specimen number 1 and the lowest stresses exist in specimen number 6 .

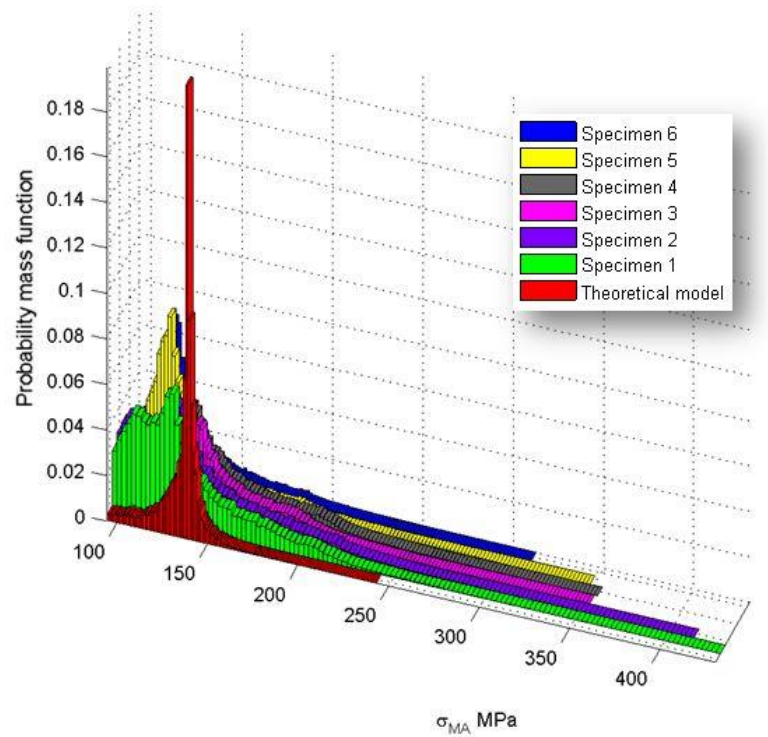

Fig. 8. Probability mass function for the Matake criterion

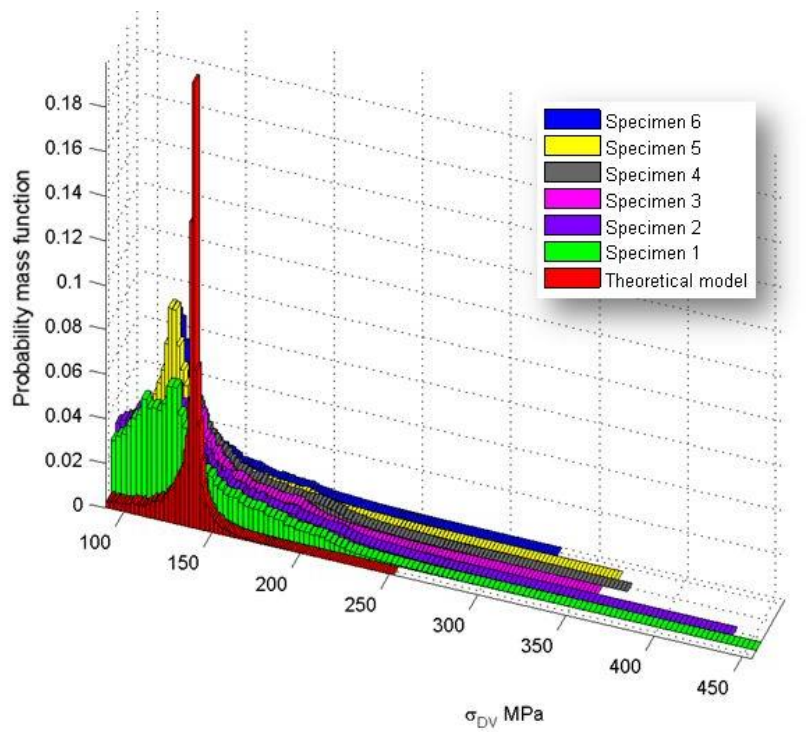

Fig. 9. Probability mass function for the Dang Van criterion

Tab. 1. Values of the maximum equivalent stresses in $\mathrm{MPa}$ (nominal stress $180 \mathrm{MPa}$ ) according to the particular hypothesis

\begin{tabular}{|c|c|c|c|c|}
\hline \multirow{2}{*}{ Specimens } & \multicolumn{4}{|c|}{ Hypothesis } \\
\cline { 2 - 5 } & HMH & S1 & MA & DV \\
\hline theoretical & 303.7 & 316.9 & 243.2 & 252.7 \\
$\mathbf{1}$ & $\underline{\mathbf{5 1 8 . 5}}$ & $\underline{\mathbf{5 6 0 . 9}}$ & $\underline{\mathbf{4 3 0 . 5}}$ & $\underline{\mathbf{4 5 5 . 0}}$ \\
2 & 494.7 & 538.1 & 413.2 & 438.9 \\
3 & 446.2 & 459.6 & 352.9 & 359.9 \\
4 & 432.1 & 461.5 & 354.5 & 374.1 \\
5 & 423.3 & 452.6 & 347.7 & 366.0 \\
6 & 380.9 & 406.7 & 312.6 & 328.8 \\
\hline
\end{tabular}




\section{EXPERIMENTAL TESTS}

The analysed specimens were experimentally tested under cyclic push-pull loading with controlled nominal stress amplitude $\sigma_{a n}$. The fatigue lives $N_{\text {exp }}$ until complete rapture of the specimens are reported in Tab. 2.

Tab. 2. Results of experimental push-pull tests

\begin{tabular}{|c|c|c|}
\hline Specimens & $\boldsymbol{\sigma}_{\boldsymbol{a n}}, \mathbf{M P a}$ & $\boldsymbol{N}_{\text {exp }}$, cycles \\
\hline 1 & 180 & 146200 \\
\hline 2 & 180 & 169590 \\
\hline 3 & 180 & 267350 \\
\hline 4 & 180 & 85260 \\
\hline 5 & 180 & 38530 \\
\hline 6 & 180 & 39400 \\
\hline
\end{tabular}

\section{ANALYSIS OF THE RESULTS}

Experimental fatigue lives of the tested specimens exhibit large scatter. The ratio between longest fatigue life to shortest is equal to $6.9\left(\max \left(\mathrm{N}_{\exp }\right) / \min \left(\mathrm{N}_{\text {exp }}\right)\right)$ and the ratios in respect to mean value is 2.1 and $0.31\left(\max \left(\mathrm{N}_{\exp }\right) /\right.$ mean $\left(\mathrm{N}_{\exp }\right)$ and $\min \left(\mathrm{N}_{\exp }\right) /$ mean $\left(\mathrm{N}_{\mathrm{exp}}\right)$ ). It was expected that fatigue lives obtained under the same nominal stress amplitude (180 MPa) could be correlated with maximum value of local stress computed using FEM and real shape of the weld joints. Fig. 10 presents no correlation between experimental fatigue lives $\mathrm{N}_{\text {exp }}$ and maximum stresses computed according to analyzed hypothesis. Moreover, in spite of multiaxial stress state due to high stress concentration and different function for equivalent stresses, the relation between computed maximal stresses $\sigma_{\text {HIP }}$ and fatigue lives $\mathrm{N}_{\text {exp }}$ for all hypothesis has the same character. The trials to find the correlation between parameters of the pmf functions and experimental fatigue lives were not successful. However, it must be remembered that the pmf shows the probability of occurrence of equivalent stress value in the weld joint volume without consideration of its location in the joint.

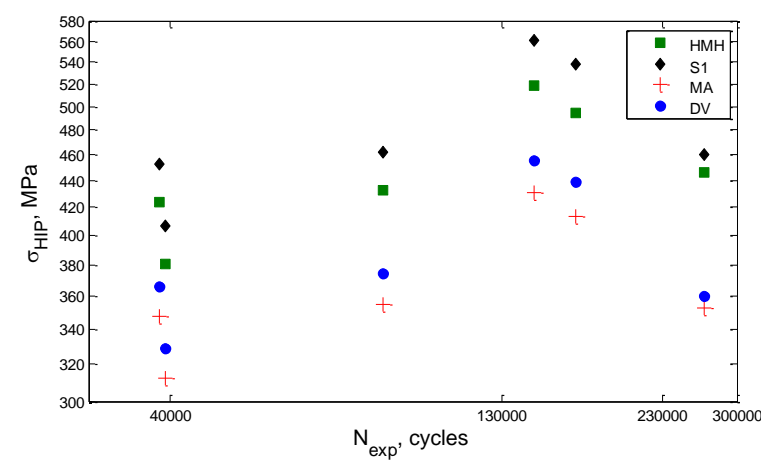

Fig. 10. Relation between number of cycles to failure $\mathrm{N}_{\exp }$ and maximum values of equivalent stresses for the analysed hypotheses

\section{CONCLUSIONS}

The graph of the probability mass function allows analysing the probability of occurrence of equivalent stress values and its inhomogeneous distribution. From the comparison of the results obtained from the real (specimen) and the reference (theoretical) elements it can be stated that the stresses in the real structure are higher and larger volume of joint is exposed to high (greater than nominal) stresses.

Experimental tests for a given number of specimens showed lack of convergence between the highest equivalent stresses and the lowest fatigue lives. Similar conclusions were obtained by Hou C-Y (2007) but they are in contrary to results obtained by Chapettii M.D. et al (1995). However, it must be noted that Chapettii M.D. et al (1995) did not calculate stresses using real surface topography but they compared experimental fatigue life obtained for specimens with different toe weld period.

Moreover, in spite of different assumptions made in the analysed fatigue criteria the maximal equivalent stresses changes in proportional way between the analysed fatigue criteria (Fig. 10).

It turns out that the changes in geometry of the weld joint surface and stress concentration due this fact is not dominating in fatigue damage process. It is necessary in the calculations to take into account other factors affecting fatigue life such as:(i) initial deformation of specimen caused by weld shrinkage,(ii) stress distribution (not only the highest stress, crack coalescence), (iii) stress gradient effect, (iv) residual stress distribution.

\section{REFERENCES}

1. Alam M.M., Barsoum Z., Jonsén P., Kaplan A.F.H., Häggblad H.A (2010), The Influence of Surface Geometry And Topography on the Fatigue Cracking Behaviour of laser Hybrid Welded Eccentric Fillet Joints, Applied Surface Science, 256, 1936-1945.

2. Blacha K., Karolczuk A., Bański R., Stasiuk P. (2011a), Experimental Study of Fatigue Life of Cruciform Welded Joints with Reference to Scale Effect, Acta Mechanica et Automatica, Vol 5, No.3, $16-20$ (in Polish).

3. Blacha Ł., Karolczuk A., Łagoda T. (2011b), Modeling of Stress in Welded Joints Under Consideration of Plastic Strains in Fatigue Life Calculations, Materials Testing, vol 53, 339-343.

4. Chapetti M.D., Otegui J.L. (1995), Importance of Toe Irregularity for Fatigue Resistance of Automatic Welds, International Journal of Fatigue, Vol. 17, 531-538.

5. Dang Van K.(1993), Macro-micro Approach in High-Cycle Multiaxial Fatigue, In Advances in Multiaxial Fatigue. (Edited by McDowell, D.L. and Ellis, R.) American Society for Testing and Materials STP 1191. Philadelphia, 120-130.

6. Hobbacher A. (2008), Recommendations for Fatigue Design of Welded Joint and Components, IIW document IIW-1823-07 ex XIII2151r4-07/XV-1254r4-07.

7. Hou C-Y. (2007), Fatigue Analysis of Welded Joints with the aid of Real Three-Dimensional Weld Toe Geometry, International Journal of Fatigue, 29, 772-785.

8. Karolczuk A. (2008), Non-local Area Approach to Fatigue Life Evaluation under Combined Reversed Bending and Torsion, International Journal of Fatigue, 30, 1985-1996.

9. Karolczuk A., Blacha $\llcorner$. (2011), Application of the Weakest Link Concept to Fatigue Analysis of Welded Joints, Acta Mechanica et Automatica, Vol.5 No. 3, 51-54 (in Polish).

10. Karolczuk A., Macha E. (2005), Critical Planes in Multiaxial Fatigue, Materials Science Forum, Vol. 482, 109-114.

11. Matake T. (1977), An Explanation on Fatigue Limit under Combined Stress. Bulletin of the The JapanSociety of Mechanical Engineers 20, 257-263.

12. Stewart W.J. (2011), Probability, Markov Chains, Queues, and Simulation.The Mathematical Basis of Performance Modeling. Princeton University Press, 105.

The project financed from the funds of the National Centre of Science decision number 2011/01/B/ST8/06850. 